\title{
Experimental Model Study of the Physical Mechanisms \\ Governing Blast Furnace Hearth Drainage*
}

\author{
By W.B.U. TANZIL,** P. ZULLI,** J.M. BURGESS*** \\ and $W . V$. PINCZEWSKI**
}

\begin{abstract}
Synopsis
Previous studies concerned with the drainage of the blast furnace hearth have assumed that the iron-slag interface remains horizontal and fixed at the level of the taphole during the outflow of the slag phase. As a consequence they have ignored the presence of the iron phase and its effect on the drainage characteristics of the slag phase.

In this study we examine the validity of the above assumption using a novel two-dimensional experimental drainage apparatus which allows a clear visualisation of the drainage behaviour of two immiscible fluids. The results of the study suggest that in most cases the iron and slag phases may be expected to flow simultaneously from the taphole and that the iron-slag interface will not remain horizontal and fixed at the level of the taphole as has been previously assumed.

It is shown that the drainage process is characterised by a down-ward tilting of the gas-slag interface towards the taphole and a simultaneous downward tilting of the iron-slag interface away from the taphole. The experiments show that it is possible to drain the iron phase down to levels considerably below the level of the taphole. The volume of iron removed below the level of the taphole increases with increasing slag drainage rate. Calculations are presented which suggest that under actual blast furnace conditions this volume may be of the same order as the volume of residual slag remaining above the level of the taphole at the end of tapping.

Finally, it is concluded that existing predictions of slag residual ratio based on studies which have neglected the presence of the lower iron phase may lead to a serious underprediction of the residual ratio particularly at higher slag drainage rates.
\end{abstract}

\section{Introduction}

The effective drainage of molten slag from the hearth can be a major problem in the operation of large, high productivity ironmaking blast furnaces. ${ }^{1-3)}$ Failure to drain the hearth effectively results in high liquid levels within the hearth and this has an adverse effect on furnace stability, productivity and efficiency. ${ }^{6}$ In particular, for operations characterised by high slag to metal volume ratios, hearth drainage can be the single most important factor in limiting furnace productivity and efficiency. It is therefore important for furnace operators to understand the physical mechanisms governing hearth drainage.

In large blast furnaces the hearth is packed with coke $^{1)}$ and the void space is occupied by molten iron and slag which accumulate as a result of the reducing reactions in the upper zones of the furnace. The molten iron and slag are immiscible and as a result of gravity they segregate into two separate layers. The lower layer is the heavier iron phase (specific gravity approximately 6.8) and the upper layer is the lighter slag phase (specific gravity approximately 2.8). A schematic of this condition is shown in
Fig. 1. The hearth is drained from a taphole located in the side of the furnace. The draining process or casting is terminated when furnace gas blows from the taphole. Because of the importance of liquid level in the hearth in determining furnace performance, the problem of estimating the volume of molten iron and slag which remain in the hearth at the end of casting is central to the development of effective operational strategies for large furnaces.

A number of studies, both experimental and theoretical, concerned with estimating the residual liquid volume after casting have been reported. ${ }^{2-6}$ ) These studies have all considered the drainage of a single liquid (slag phase) from a packed bed and have ignored the presence of the second liquid phase (iron phase). This was justified on the basis of the low viscosity of the iron relative to that of the slag. It was argued that because of its low viscosity low pressure gradients would be associated with the flow of the iron and that this would result in the iron being drained down to the level of the taphole and the ironslag interface remaining horizontal and stationary during the subsequent drainage of the slag phase.

The above assumption implies that the iron and slag phases flow from the furnace separately. The iron phase flows first and when the iron-slag interface reaches the taphole the iron flow ceases and the slag flow begins. This behaviour is at variance with recently reported drainage behaviour from a large, high productivity blast furnace ${ }^{1)}$ which shows that both iron and slag flow from the furnace simultaneously over the greater part of the period for which the taphole is open. This behaviour cannot be predicted by the existing single-liquid models for hearth drainage. Further, it suggests that errors may be introduced in estimating residual volumes when ap-

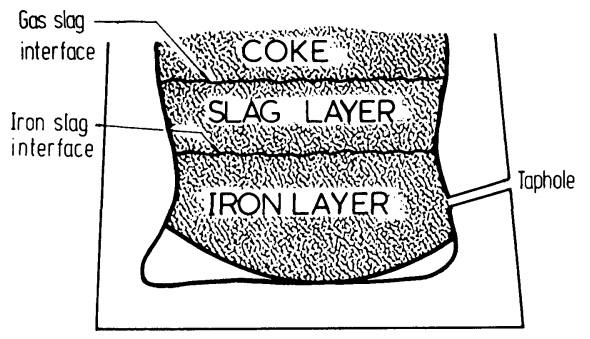

Fig. 1. Schematic of iron and slag distribution in a blast furnace hearth of large diameter.

* Presented to the 103rd ISIJ Meeting, April 1982, S111, at Tokyo Institute of Technology in Tokyo. Manuscript received July 21, 1983. (C) 1984 ISIJ

** School of Chemical Engineering and Industrial Chemistry, University of New South Wales, Kensington, N.S.W., 2033 Australia.

*** Department of Chemical Engineering, University of Queensland, St. Lucia, Queensland, 4067 Australia. 
plying the results of these single-liquid studies to large operating furnaces because these studies have neglected the interaction between the drainage of the iron and slag phases.

The purpose of the present study is to identify the major physical processes which govern the interaction between the drainage of two liquid phases. The study is therefore concerned with the simultaneous drainage of two immiscible liquids from a packed bed. A novel experimental apparatus is introduced which clearly demonstrates the interaction between the two draining phases. Although the actual hearth drainage problems is three-dimensional, the twodimensional study is useful both in identifying the physical processes which determine the nature of the interaction between the two draining phases and in testing the validity of the assumptions made in the development of mathematical models which will form the basis for predicting conditions within actual operating furnaces. A companion paper outlines the details of such a numerical model and a comparison is made there between the predicted positions of both the gas-liquid and liquid-liquid interfaces as a function of time with the experimentally measured positions reported in this study.

\section{Physical Modelling of Drainage of Two Im- miscible Liquids}

In physical models of the hearth drainage process the coke bed is usually represented by a bed of glass beads in a transparent container. ${ }^{2-5}$ ) This allows the position of the gas-liquid interface to be observed during a drainage experiment. A problem with this type of model is that it is difficult to resolve the position of the interface accurately because of the difficulty in transmitting light through the packed bed and because of the presence of a small capillary effect which tends to smear the interface. In cases where the flow is two-dimensional these difficulties may be eliminated and a considerable improvement in flow visualization achieved by replacing the packed bed with a viscous flow analogue. ${ }^{9)}$

The viscous flow analogue is based on the similarity between the differential equations governing the viscous flow of a liquid through a packed bed (Darcy's law) and those for the flow of a viscous liquid between two closely spaced parallel plates.

If the liquid between the plates is incompressible, the Navier-Stokes equation for the flow is

$$
\rho\left(\frac{\partial \bar{V}}{\partial t}+\bar{V} \cdot \nabla \bar{V}\right)=-\nabla P+\rho \bar{g}+\mu \nabla^{2} \bar{V}
$$

For conditions when Darcy's law is applicable (creeping flow) we may neglect inertial terms, i.e., the R.H.S. of Eq. (1). If the spacing between the plates (b) is sufficiently small, the flow is very nearly two-dimensional in the $x-y$ plane and the velocity gradients in the direction normal to the plates ( $z$ direction) are much larger than in $x$ and $y$ directions. With these assumptions Eq. (1) may be written as

$$
\begin{aligned}
& \frac{-\partial P}{\partial x}+\rho g_{x}+\mu \frac{\partial^{2} v_{x}}{\partial z^{2}}=0 \\
& \frac{-\partial P}{\partial y}+\rho g_{y}+\mu \frac{\partial^{2} v_{y}}{\partial z^{2}}=0
\end{aligned}
$$

Integrating Eqs. (2) and (3) twice with respect to $z$ with boundary conditions

and

$$
z=0, \quad \frac{\partial v_{x}}{\partial z}=\frac{\partial v_{y}}{\partial z}=0
$$$$
z= \pm \frac{b}{2}, \quad v_{x}=v_{y}=0
$$

we obtain

$$
\begin{aligned}
& v_{x}=\frac{1}{z \mu}\left(z^{2}-\frac{b^{2}}{4}\right) \frac{\partial}{\partial x}\left(P-\rho g_{x} x\right) \\
& v_{y}=\frac{1}{z \mu}\left(z^{2}-\frac{b^{2}}{4}\right) \frac{\partial}{\partial y}\left(P-\rho g_{y} y\right)
\end{aligned}
$$

Averaging the above equations over the distance between the plates and defining a hydraulic potential $\phi$ (with $g_{x}=0, g_{y}=g$ )

$$
\phi=\frac{P}{\rho g}+y
$$

We have

$$
\begin{aligned}
& \bar{v}_{x}=\int_{b / 2}^{b / 2} v_{x}(z) d z=u=-\frac{b^{2}}{12} \cdot \frac{\rho g}{\mu} \cdot \frac{\partial \phi}{\partial x} \\
& \bar{v}_{y}=\int_{-b / 2}^{b / 2} v_{y}(z) d z=v=-\frac{b^{2}}{12} \cdot \frac{\rho g}{\mu} \cdot \frac{\partial \phi}{\partial y}
\end{aligned}
$$

The corresponding velocities for a Darcy flow through a packed bed are given by

$$
\begin{aligned}
& u=-K \frac{\partial \phi}{\partial x} \\
& v=-K \frac{\partial \phi}{\partial y}
\end{aligned}
$$

where, $K:$ the hydraulic conductivity of the fluid $\phi:$ the potential driving the flow.

The similarity between Eqs. ((7) and (8)) and Eqs. ((9) and (10)) is apparent with the hydraulic conductivity, $K$, in the packed bed being equivalent to

$$
\kappa=\frac{\rho g b^{2}}{12 \mu}
$$

The analogy is shown schematically in Fig. 2. By selecting appropriate values of plate spacing, $b$, it is possible to model a wide range of hydraulic conductivities using a limiting range of liquids (i.e., $\rho$ and $\mu$ ).

The viscous flow analogue has been extensively used in the investigation of groundwater flows. ${ }^{\text {7) }}$ Since it allows an unhindered visualisation of sharply defined interfaces, it is particularly suited to the needs of the present study where it is required to simultaneously observe the positions of two interfaces (gas-liquid and liquid-liquid).

\section{Experimental Model}

The viscous flow analogue used in the present study is shown in Fig. 3 and Photo. 1. It consists of two parallel plexiglass plates $(834 \mathrm{~mm}$ wide and 
VISCOUS FLOW ANALOGUE FOR PACKED BED DRAINAGE

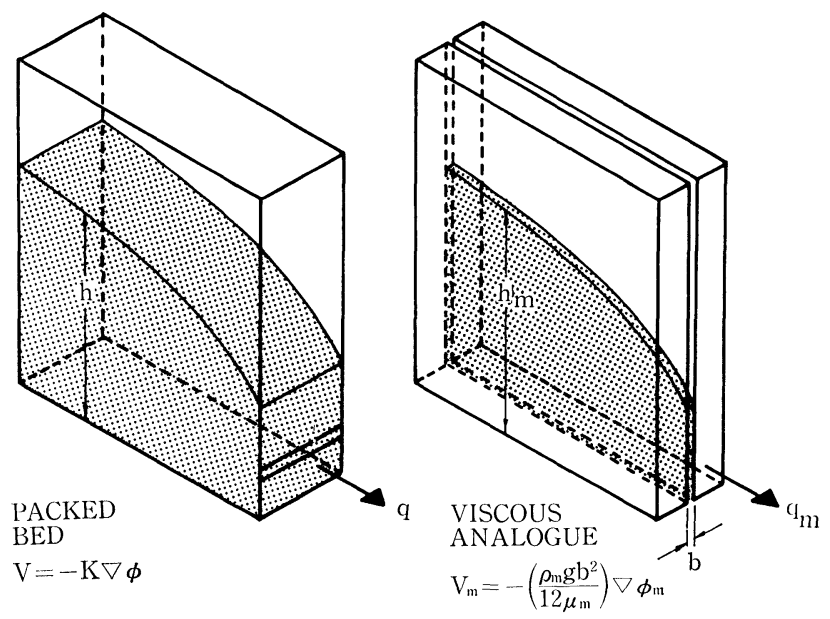

Fig. 2. Viscous flow analogue for flow in a packed bed and flow between two parallel plates.

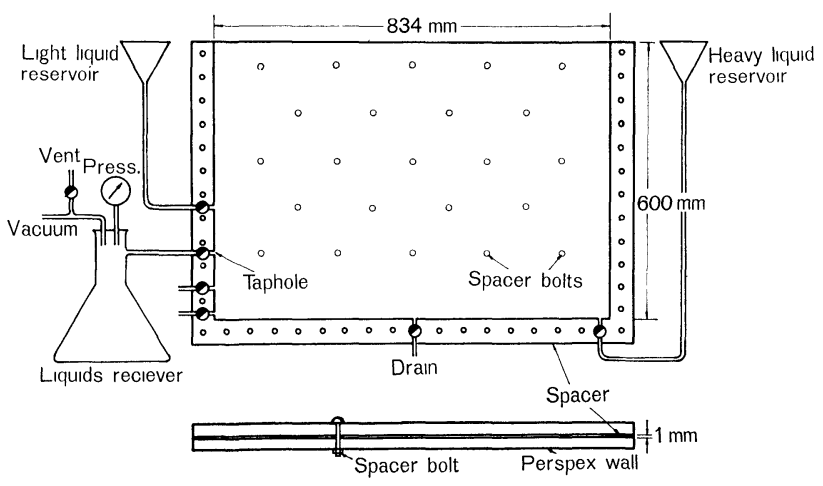

Fig. 3. Experimental viscous flow analogue.

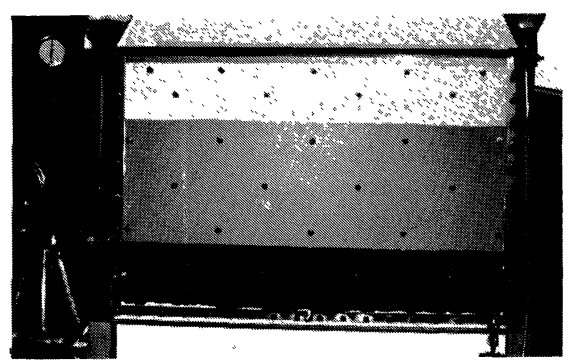

Photo. 1. Experimental apparatus.

$600 \mathrm{~mm}$ high) spaced at a distance of approximately $1 \mathrm{~mm}$. The spacing is maintained uniform by a number of stainless steel spacer bolts and washers. The edges of the model are sealed with a stainless steel gasket which has the same thickness as the spacer washers. A number of ports are cut into this gasket to allow fluids to be charged or withdrawn from the model. The port through which fluid is withdrawn (the taphole) is connected to a needle valve which is in turn connected to an evacuated chamber. The combination of needle valve and vent on the evacuated chamber allows a wide range of fluid withdrawal rates to be set. The experimental fluids used are air, various mixtures of glycerol and water, and mercury.
These are the experimental analogues for furnace gas, slag and iron phases, respectively.

Before each drainage experiment the model was filled with mercury and glycerol-water mixture to the desired levels and the contents allowed to attain gravity equilibrium (i.e., both gas-liquid and liquid-liquid interfaces horizontal-see Photo. 1). Each drainage experiment consisted of opening the taphole (needle valve) and photographically recording the positions of both interfaces as a function of time until the gas-liquid interface reached the taphole.

\section{Experimental Results}

Experiments were conducted with the initial position of liquid-liquid (iron-slag) interface above, at, and below the level of the taphole. Preliminary findings have been reported in Pinczewski et al. ${ }^{8)}$ and Burgess et al. ${ }^{9)}$ A cine film of the experiments is available from the authors on request.

\section{Initial Liquid-Liquid Interface above Level of Taphole}

A photographic sequence of this drainage experiment is shown in Photo. 2. Since the mercury level is above the taphole, mercury is the first phase to flow out. The mercury-only flow continues until the mercury-glycerol interface reaches the level of the taphole $(0 \sim 7 \mathrm{sec})$. During this period both the air-glycerol and mercury-glycerol interfaces remain essentially horizontal. When the mercury-glycerol interface reaches the taphole the glycerol phase begins to flow out. The flow of mercury continues uninterrupted with both glycerol and mercury flowing simultaneously from the taphole. The simultaneous flow of both phases continues until the end of the experiment $(7 \sim 18 \mathrm{sec})$ when the air-glycerol interface reaches the taphole and air blows out of the model.

During the period of simultaneous mercury-glycerol flow, the air-glycerol interface tilts towards the taphole in a manner similar to that previously reported in single-liquid drainage studies. ${ }^{2-6)}$ The mercury-glycerol interface remains at the taphole tilting downwards away from the taphole as mercury continues to be drained. At the completion of the drainage experiment (Photo. 2(d)) the mean mercury level is considerably lower than the level of the taphole.

As previously reported for single-liquid studies, a considerable volume of the more viscous phase (glycerol) remains undrained in the model. In the present experiment we additionally observe that a considerable volume of the heavier phase (mercury) is drained to levels well below that of the taphole.

\section{Initial Liquid-Liquid Interface at the Taphole}

In this experiment both the mercury and glycerol are present at the taphole at the commencement of drainage and both phases flow out simultaneously. The drainage sequence is identical to that observed in the previous experiment from the time that the mercury-glycerol interface first reached the taphole (i.e., from Photo. 2(b) onwards). The simultaneous flow of both phases continues until the termination of the drainage process by the arrival of the gas-liquid 

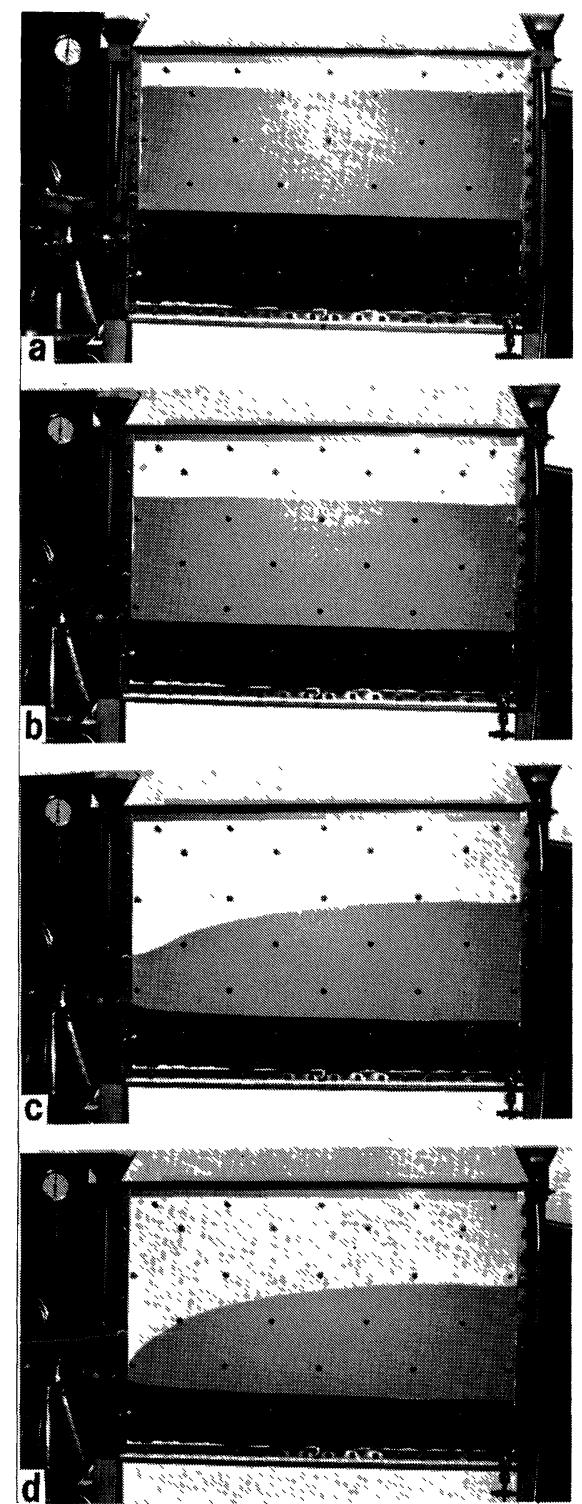
(a) $t=0 \mathrm{sec}$
(b) $t=7 \mathrm{sec}$
(c) $t=12 \mathrm{sec}$
(d) $t=18 \mathrm{sec}$

Photo. 2. Drainage experiment A. Initial liquid-liquid interface above level of taphole.

interface at the taphole. As before, the mercuryglycerol interface tilts downwards away from the taphole and a substantial volume of mercury is drained from below the level of the taphole.

\section{Initial Liquid-Liquid Interface below Level of Taphole}

A photographic sequence from this drainage experiment is shown in Photo. 3. Since glycerol is the only phase initially at the taphole it flows out first. The flow of glycerol is accompanied by a relatively rapid upward movement of the mercury-glycerol interface towards the taphole (Photo. 3(b)). When the mercury-glycerol interface reaches the taphole (Photo. 3(c)) both phases drain simultaneously and from this point the drainage process proceeds in a manner similar to that observed in the previous experiments. The simultaneous flow of both phases
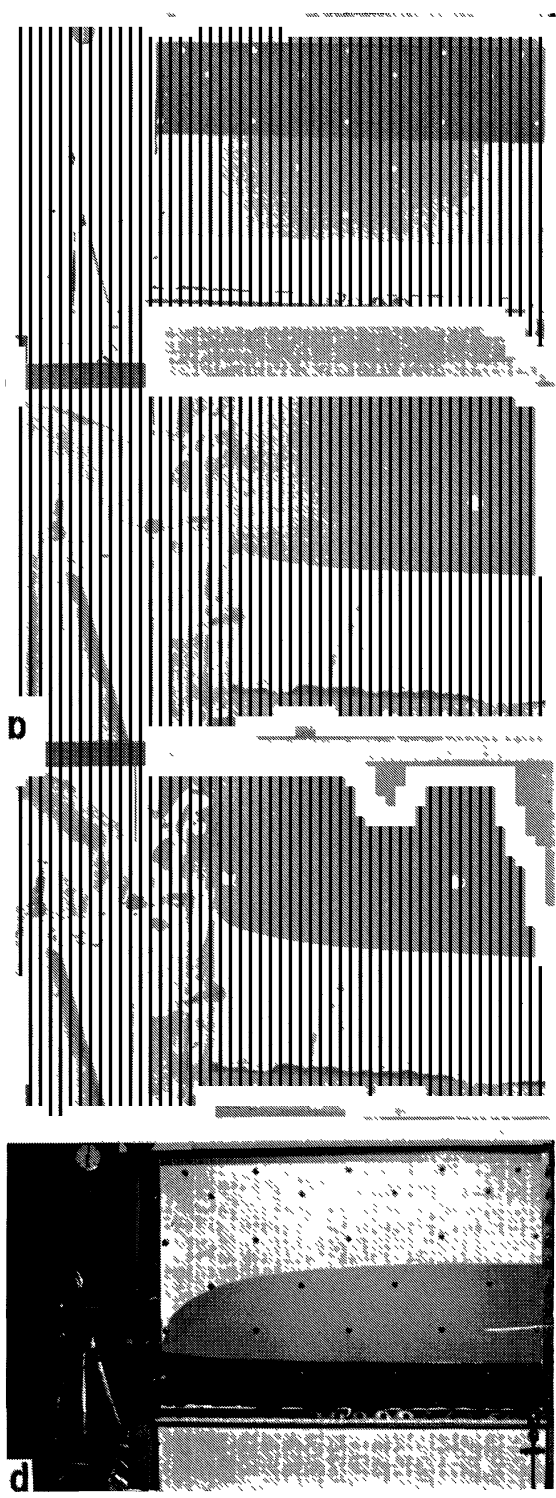
(a) $t=0 \mathrm{sec}$
(b) $t=0.5 \mathrm{sec}$
(c) $t=1.0 \mathrm{sec}$
(d) $t=12.0 \mathrm{sec}$

Photo. 3. Drainage experiment C. Initial liquid-liquid interface below level of taphole.

continues until the gas-liquid interface reaches the taphole (Photo. 3(d)). Although the initial level of the mercury was considerably below that of the taphole, it was still possible to drain mercury from the model.

\section{Discussion}

The drainage behaviour observed in the above experiments can be readily understood from a consideration of the relative magnitude of the viscous and gravitational forces acting on the individual interfaces. Because of the converging nature of the flow, velocities in the vicinity of the taphole are high and substantial localised pressure gradients are established close to the taphole. The associated viscous forces act to draw the upper (gas-liquid) interface down towards the taphole and the lower (liquid-liquid) 
interface up towards the taphole. The gravitational force opposes any such deviation of the interface from the horizontal. The resultant motion and shape of the interfaces depend on the viscous/gravity force ratio.

In the first experiment (see Photo. 1) the initial level of mercury is above the taphole and mercury is therefore first to drain from the model. Because the viscosity of mercury is relatively low, the viscous forces in the vicinity of the taphole are insufficient to overcome gravity. As a result both the gas-liquid and liquid-liquid interfaces remain essentially horizontal during the period when mercury is the only draining phase.

After the mercury-glycerol interface reaches the taphole both mercury and glycerol flow simultaneously. Because of the high viscosity of glycerol large pressure gradients are established in the vicinity of the taphole. For these conditions the viscous/gravity force ratio is sufficiently high to cause the gas-liquid interface to tilt down towards the taphole in a manner similar to that previously reported for single-liquid studies. However, contrary to the assumption made in these studies the liquid-liquid interface does not remain horizontal and fixed at the level of the taphole. This is because the viscous/gravity force ratio is sufficient to maintain the liquid-liquid interface at the taphole and allow the lower phase to be drained even when the mean level of the liquid-liquid interface is below the level of the taphole. The result is a downward tilt of the liquid-liquid interface away from the taphole. This drainage behaviour was first predicted theoretically by Pinczewski et al. ${ }^{8)}$ and later by Tamiya et al. ${ }^{10)}$ The present study provides the first experiment confirmation of this drainage phenomena.

In the final experiment (see Photo. 3) where the initial level of the liquid-liquid interface is below the level of the taphole the pressure gradients developed in the vicinity of the taphole by the flow of the highly viscous upper phase are sufficient to draw the liquidliquid interface towards the taphole and quickly establish simultaneous flow of both phases from the taphole. If the pressure gradient is not sufficient to draw the liquid-liquid interface all the way to the taphole then the interface will take up some intermediate position similar to that shown in Photo. 4(b). Here, although the lower phase is not flowing (i.e., not being drained from the model), the liquid-liquid interface does not remain horizontal but deforms to a position governed by the requirements for equilibrium between the viscous forces induced by the flow of the upper phase and the gravitational force which acts to return the interface to the horizontal position.

\section{Effect of the Drainage of the Metal Phase on Slag Residual Ratio}

In their experimental study of hearth drainage Fukutake and Okabe ${ }^{2,3)}$ assumed that the iron-slag interface remains horizontal at the level of the taphole during the drainage of the slag phase, i.e., no drainage of iron below the level of the taphole. Their experiments therefore consisted of draining a single liquid

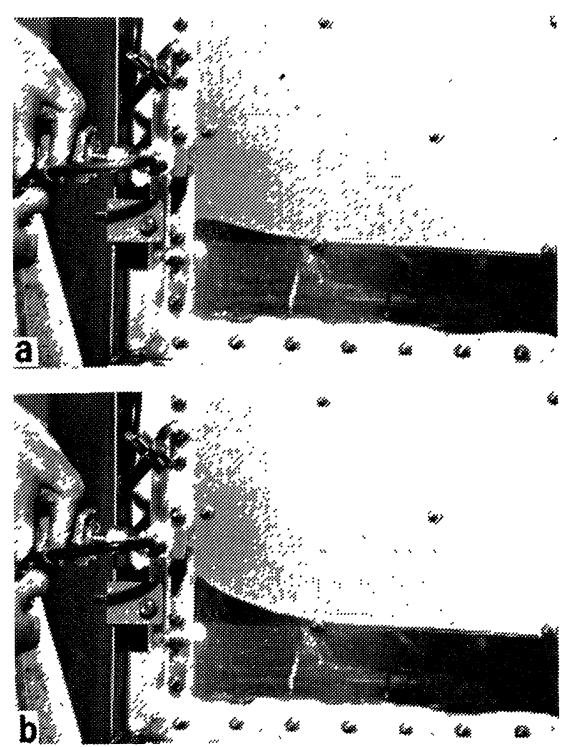

(a) $t=0.5 \mathrm{sec}$

(b) $t=1.0 \mathrm{sec}$

Photo. 4. Drainage experiment. Initial liquid-liquid interface below level of taphole.

(slag) from a cylindrical packed bed through a taphole located at the base of the bed. They correlated their experimentally determined residual liquid volumes in terms of an empirical 'flow out coefficient', $F_{L}$, given by

$$
F_{L}=\left\{180 \frac{(1-\varepsilon)^{2}}{\varepsilon^{3}} \cdot \frac{1}{\phi^{2} d^{2}} \cdot \frac{\mu}{\rho g}\right\} V_{0}\left[\frac{D}{H}\right]^{2}
$$

where, $\varepsilon$ : the porosity of the bed

$\phi:$ the sphericity of the particles

$d$ : the particle diameter

$\mu:$ the fluid viscosity

$\rho:$ the liquid density

$V_{0}$ : the liquid superficial velocity over the cross-sectional area of the bed

$g$ : the acceleration due to gravity

$H$ : the height of the initial slag layer above the base of the bed

$D$ : the bed diameter.

Fukutake and Okabe proposed that their correlation be used to estimate working liquid levels in the blast furnace hearth through an estimate of the slag residual ratio. However, since their correlation neglects the effect of the iron phase on the flow of the slag phase and completely ignores the drainage of the iron phase below the level of the taphole, their estimates of working liquid levels in the hearth may be in considerable error, particularly for conditions where the slag drainage rate is high. We are currently conducting two-liquid drainage experiments in three-dimensional beds to determine the magnitude of this error and the results of these experiments will be reported shortly. For the present it is possible to obtain a qualitative measure of the error by comparing the drainage behaviour of single-liquid and two-liquid systems using the two-dimensional viscous flow analogue. 
Following Fukutake and Okabe ${ }^{2)}$ we correlate the experimentally observed residual ratio of the upper phase (slag) utilising a flow out coefficient similar to that defined by Eq. (12). The term

$$
\left\{180 \cdot \frac{(1-\varepsilon)^{2}}{\varepsilon^{3}} \cdot \frac{1}{\phi^{2} d^{2}} \cdot \frac{\mu}{\rho g}\right\}
$$

in this equation is simply the reciprocal of the hydraulic conductivity of the slag phase, $K$, and Eq. (12) may be written as

$$
F_{L}=\frac{V_{0}}{K}\left[\frac{D}{H}\right]^{2}
$$

where, $D$ : now the width of the two-dimensional bed

$H$ : the initial height of the more viscous phase (slag) above the level of the taphole.

For the single-liquid drainage experiments shown in Fig. 4 the height of the taphole corresponds to the base of the bed whilst for the two-liquid experiments it corresponds to the initial level of the liquid-liquid interface.

It is significant that data for both the single-liquid and two-liquid experiments shown in Fig. 4 appear to be well correlated by the flow out coefficient. Figure 4 shows that there is a small but consistent difference between the residual ratios for the glycerol phase between the single-liquid and two-liquid experiments. At low values of the flow out coefficient (low drainage rates) both experiments result in similar values for the residual ratio. Here, because of the low glycerol flow rate, the pressure gradients induced by the glycerol flow are insufficient to significantly distort the mercury-glycerol interface which therefore behaves like the fixed solid boundary of the base of the model in the single-liquid experiments. However, as the flowrate of the glycerol phase increases (higher values of $F_{L}$ ) the viscous/gravitational force ratio increases and there is a greater deformation of the mercury-glycerol interface and significant drainage of mercury from below the level of the taphole. The drainage of mercury below the level of the taphole

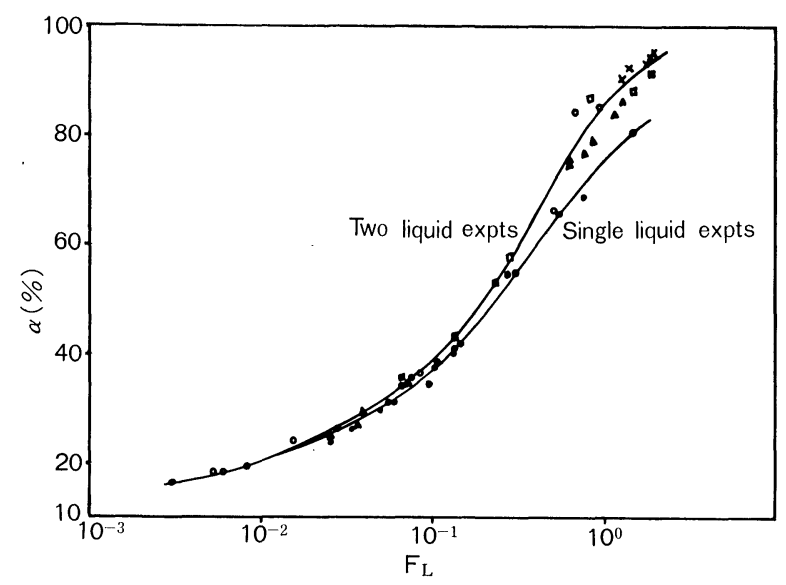

Fig. 4. Comparison between residual glycerol ratio measured in single-liquid and two-liquid experiments. effectively lowers the air-glycerol interface closer to the taphole. This leads to a reduction in the time required for the air-glycerol interface to reach the taphole and hence an increase in residual ratio over that which would have occurred had the mercuryglycerol interface remained horizontal at the level of the taphole, i.e., as in the single-liquid experiments. This effect of the drainage of the lower phase on the residual volume of the upper phase may be expected to increase with increasing value of the flow out coefficient (increasing viscous/gravitational force ratio) and this is in accord with the data in Fig. 4 which shows a progressive increase in the difference between the single-liquid and two-liquid drainage experiments with increasing $F_{L}$.

\section{Application to Actual Blast Furnaces}

The drainage behaviour observed in the above experiments provides a qualitative explanation for the drainage behaviour experienced with actual operating blast furnaces. As an example of this we consider the drainage behaviour of No. 5 blast furnace at Australian Iron and Steel Pty. Ltd., Port Kembla. This furnace is of medium size $\left(3000 \mathrm{~m}^{3}\right.$ internal volume) with three tapholes and a daily production of approximately $6000 \mathrm{t}$ of hot metal. The slag volume ratio for the furnace is high, at approximately $370 \mathrm{~kg} / \mathrm{t}$ hot metal, and adequate hearth drainage can be a problem. When a taphole is opened at the commencement of a cast, it is possible to observe three distinct types of flow depending on the condition of the hearth prior to tapping. Most commonly, both slag and metal flow from the taphole simultaneously and this is termed a 'together' cast. Alternatively, it is possible to initially observe either metal or slag to flow alone and these are termed 'metal first' and 'slag first' casts, respectively. These casts eventually lead to a period where both iron and slag flow out simultaneously. The 'metal first', ' together' and 'slag first' casts clearly correspond to the three model experiments $\mathrm{A}, \mathrm{B}$, and $\mathrm{C}$ where the initial level of the liquid-liquid interface is above, at and below the level of the taphole, respectively.

The 'together' and 'metal first' casts are readily understood by furnace operators. However, the "slag first' cast has always been considered anomalous since the furnace operator always anticipates a 'metal first' or 'together' cast when this occurs. The above drainage experiments explain this apparent anomaly. 'Slag first' casts occur only because it is possible to drain the metal phase to levels well below the level of the taphole. When the iron-slag interface is initially below the level of the taphole the slag is the first phase to flow and the pressure gradient in the vicinity of the taphole draws the iron-slag interface towards the taphole (see Photo. 3). The characteristic time for the iron-slag interface to respond is short in comparison to the total cast time and if the viscous force on the iron-slag interface generated by the flow of the slag phase is sufficient to overcome the gravitational force restraining the interface, then 
simultaneous flow of both iron and slag is quickly established at the taphole. If the pressure gradient is not sufficient to overcome the gravitational force (i.e., the initial level of the iron-slag interface is considerably below the level of the taphole or slag drainage rate is low) the iron-slag interface adopts an intermediate position relative to the taphole (similar to that shown in Photo. 4(b)). Slag continues to flow alone until such time that the average level of the iron-slag interface increases. This occurs as a result of either the continued accumulation of iron or, the slag flow rate increasing as a result of erosion of the taphole, i.e., increase in taphole diameter. Both of these effects occur together in actual operating furnaces. The reason for the furnace operator not anticipating this sequence of events is that he does not consider the possibility of iron being drained to a level below that of the taphole.

Although the effect of mercury on the residual ratio of glycerol in our experiments is relatively small it may be anticipated that this effect will be considerably larger for actual blast furnace hearth drainage conditions. The magnitude of the gravitational force, i.e., the force opposing the tilting of the liquidliquid interface from the horizontal, is proportional to the density difference between the two liquids, $\Delta \rho$. For the mercury-glycerol system used in the experiments $\Delta \rho$ is approximately 12.5 whilst in a blast furnace hearth $\Delta \rho$ is only of the order 4 , i.e., the force restraining the interface is considerably lower for the blast furnace iron-slag system. As a result it is easier to deform the iron-slag interface and to drain the iron phase to levels below that of the taphole.

The above argument may be quantified by analysing the situation shown schematically in Fig. 5. We may consider this to be a special limiting case where the pressure gradient associated with the flow of the $S$-phase $\left(q_{s}\right)$ at the instant when drainage is terminated by arrival of the $G-S$ interface at the taphole, is just sufficient to draw the $I-S$ interface to within an infinitesimal distance below the taphole, i.e., no flow of the $I$-phase. If the face at $x=D$ is sufficiently far from the taphole, then the pressure variation along $x=D$ will be hydrostatic. Neglecting surface tension we can therefore relate the pressure

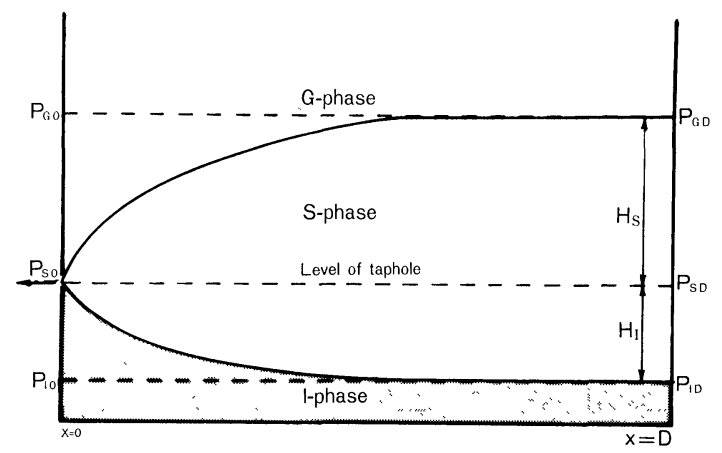

Fig. 5. Schematic of special limiting case where the viscous/ gravitational force ratio at the termination of drainage is just sufficient to maintain the liquid-liquid interface at the level of the taphole. in the gas phase at the $G-S$ interface at $x=D\left(P_{G, D}\right)$ and the pressure in the $I$-phase at the $I-S$ interface at $x=D\left(P_{I, D}\right)$ to the corresponding pressure in the $S$-phase at the level of the taphole $\left(P_{S, D}\right)$ by

$$
\begin{aligned}
& P_{G, D}=P_{S, D}-\rho_{S} g H_{S} \\
& P_{I, D}=P_{S, D}+\rho_{S} g H_{I}
\end{aligned}
$$

Since the $I$-phase is stationary $\left(q_{I}=0\right)$ the pressure at any level is uniform throughout the phase and we have

$$
P_{I, 0}=P_{I, D}
$$

Further, assuming for the moment that the gas phase is also stationary (certainly true for the model drainage experiments) we may also write

$$
P_{G, 0}=P_{G, D}
$$

Again, neglecting capillary pressure we express the pressure of the $S$-phase at the taphole $\left(P_{S, 0}\right)$ in terms of $P_{G, 0}$ and $P_{I, 0}$ as

$$
\begin{aligned}
& P_{S, 0}=P_{G, 0}+\rho_{G} g H_{S} \\
& P_{S, 0}=P_{I, 0}-\rho_{I} g H_{I}
\end{aligned}
$$

Substituting Eqs. (14) to (17) into Eqs. (18) and (19) and equating the results we have

$$
\frac{H_{I}}{H_{S}}=\frac{\rho_{S}-\rho_{G}}{\rho_{I}-\rho_{S}}
$$

or, since the $G$-phase (gas) gravity is usually much smaller than the $S$-phase (slag) gravity, we may write

$$
\frac{H_{I}}{H_{S}}=\frac{\rho_{S}}{\rho_{I}-\rho_{S}}
$$

Glearly, this ratio is closely related to the ratio of the residual volumes of the $I$ and $S$ phases, respectively. Moreover, since we have made no assumptions regarding the geometry of the system, Eqs. (20) and (21) hold both for two-dimensional and threedimensional beds, i.e., both for the experimental system and actual blast furnace hearths. This is a very important result which is not immediately obvious.

Utilising Eq. (21) or Eq. (20) with the experimental system $\rho_{S}=1.1$ and $\rho_{I}=13.6$ and typical blast furnace hearth $\rho_{S}=2.8$ and $\rho_{I}=6.8$, we have that

$$
\left(\frac{H_{I}}{H_{S}}\right)_{\text {expt. }}=0.09
$$

and

$$
\left(\frac{H_{I}}{H_{S}}\right)_{\text {actual }}=0.70
$$

Equation (22) shows that for the experimental system we may anticipate being able to drain only a small volume of the lower (mercury) phase (below the level of the taphole) (i.e., less than $10 \%$ of the residual volume of the upper (glycerol) phase). This is consistent with our drainage experiments and the observed small difference between the residual ratio curves for the single-liquid and two-liquid 
drainage experiments shown in Fig. 4. However, for actual furnace hearth conditions Eq. (23) shows that we may expect to drain substantial volumes of iron below the level of the taphole and we conclude that the average level of the iron-slag interface may be well below the level of the taphole.

The effect of draining iron below the level of the taphole is to lower the average level of the gas-slag interface closer to the taphole. Since the flow-out coefficient for the slag phase is dependent on the height of the gas-slag interface above the taphole $\left(H_{S}\right)$-see Eq. (13),

$$
F_{L} \propto\left(\frac{D}{H_{S}}\right)^{2}
$$

the overall effect is to increase the slag flow-out coefficient and therefore to increase the slag residual ratio. This argument is consistent with the experimental results shown in Fig. 4 and suggests that singleliquid study results (Fukutake and Okabe ${ }^{2)}$ ) may be used to estimate two-liquid drainage experiments provided that an estimate of the effective lowering of the slag level, i.e., increase in $F_{L}$, is available.

Because of the highly converging nature of the flow in an actual blast furnace hearth the gas-slag and iron-slag interfaces will be approximately horizontal except in a small region close to the taphole. We can therefore estimate the fraction of the total height of the slag column which is below the level of the taphole at the end of tapping $\left(H_{I} /\left(H_{I}+H_{S}\right)\right.$ see Fig. 5) from Eq. (23) as

$$
\frac{H_{I}}{H_{I}+H_{S}}=0.41
$$

i.e., $41 \%$ of the total residual slag volume is below the level of the taphole.

Equation (25) shows that in comparison to a singleliquid experiment where the initial height of the slag column above the taphole is $H_{S}^{(1)}$, the average height of the slag column in the corresponding two-liquid experiment is approximately $20 \%$ lower, i.e., $H_{S}^{(2)} \cong$ $0.8 H_{S}^{(1)}$, as a result of iron being drained from below the level of the taphole. Substituting into Eq. (24) gives

$$
\frac{\left(F_{L}^{(2)}\right)_{\text {effective }}}{F_{L}^{(1)}}=1.6
$$

Using the single-liquid drainage correlation developed by Fukutake and $\mathrm{Okabe}^{2)}$ for a typical drainage case where $F_{L}^{(1)}=0.10$ we have

$$
\begin{aligned}
& F_{L}^{(1)}=0.10 ; \quad \alpha^{(1)}=0.40 \\
& \left(F_{L}^{(2)}\right)_{\text {effective }}=0.16 ; \quad \alpha^{(2)}=0.52
\end{aligned}
$$

The above calculations show that for typical blast furnace hearth conditions the effect of draining iron from below the level of the taphole is to increase the slag residual ratio by some $30 \%$ over that which would be estimated from correlations which do not account for the drainage of the iron phase to levels below the level of the taphole. Potentially serious errors may therefore be introduced in estimates of residual slag ratio based on correlations which do not account for the presence of the iron phase and its effect on the drainage of the slag phase.

\section{Conclusions}

The behaviour of the blast furnace hearth drainage process is determined by the movement of both the gas-slag and iron-slag interfaces. Under most conditions iron and slag will flow simultaneously for some of the period over which the taphole is open. It is possible to drain the iron phase to levels considerably below the level of the taphole. This effectively reduces the distance between the gas-slag interface and the taphole and therefore increases the slag residual volume at the time when gas blows from the taphole. The total volume of iron drained from below the level of the taphole increases with increasing slag flow rate.

The characteristic downward tilting of the gasslag interface towards the taphole and the iron-slag interface away from the taphole are a consequence of the viscous pressure gradients in the vicinity of the taphole which are generated by the flow of the highly viscous slag phase. The greater the slag drainage rate the greater these gradients and as a consequence, the higher the slag residual ratio and the greater the volume of iron drained from levels below the taphole.

Previous studies of blast furnace hearth drainage in which it has been assumed that the iron-slag interface remains horizontal at the level of the taphole during the drainage of the slag phase are clearly inappropriate. Correlations for slag residual ratio developed in the course of such studies may considerably underpredict the slag residual ratio under actual hearth drainage conditions. There is a need for additional studies, both experimental and theoretical, in order to arrive at satisfactory predictive techniques for estimating working fluid levels in the blast furnace hearth. The work presented in the present paper provides a rational basis on which such additional work may proceed.

\section{Nomenclature}

$b$ : spacing between plates (Hele-Shaw model) (cm)

$d: \quad$ particle diameter $(\mathrm{cm})$

$D$ : bed diameter $(\mathrm{cm})$

$F_{L}$ : flow out coefficient

$g$ : gravitational constant

$\bar{g}$ : gravity vector with components $g_{x}, g_{y}, g_{z}$ $\left(\mathrm{cm} / \mathrm{sec}^{2}\right)$

$H$ : height of liquid above taphole level $(\mathrm{cm})$

$H_{I}$ : height of iron phase $(\mathrm{cm})$

$H_{S}$ : height of slag phase $(\mathrm{cm})$

$K:$ hydraulic conductivity $(\mathrm{cm} / \mathrm{sec})$

$P$ : fluid phase pressure $\left(\mathrm{N} / \mathrm{cm}^{2}\right)$

$P_{G, 0}:$ gas phase pressure at $x=0\left(\mathrm{~N} / \mathrm{cm}^{2}\right)$

$P_{G, D}:$ gas phase pressure at $x=D\left(\mathrm{~N} / \mathrm{cm}^{2}\right)$

$P_{I, 0}:$ iron phase pressure at $x=0\left(\mathrm{~N} / \mathrm{cm}^{2}\right)$

$P_{I, D}:$ iron phase pressure at $x=D\left(\mathrm{~N} / \mathrm{cm}^{2}\right)$

$P_{S, 0}:$ slag phase pressure at $x=0\left(\mathrm{~N} / \mathrm{cm}^{2}\right)$

$P_{S, D}: \quad$ slag phase pressure at $x=D\left(\mathrm{~N} / \mathrm{cm}^{2}\right)$ 
$q_{I}$ : volumetric flowrate of iron phase per unit volume bed $\left(\mathrm{cm}^{3} / \mathrm{cm}^{2} \cdot \mathrm{sec}\right)$

$q_{S}$ : volumetric flowrate of slag phase per unit volume bed $\left(\mathrm{cm}^{3} / \mathrm{cm}^{2} \cdot \mathrm{sec}\right)$

$t$ : time (sec)

$u$ : seepage velocity in $x$-direction $(\mathrm{cm} / \mathrm{sec})$

$v:$ seepage velocity in $y$-direction $(\mathrm{cm} / \mathrm{sec})$

$V_{0}:$ liquid superficial velocity $(\mathrm{cm} / \mathrm{sec})$

$\bar{V}$ : fluid velocity vector with components $\left(v_{x}, v_{y}\right.$, $\left.v_{z}\right)(\mathrm{cm} / \mathrm{sec})$

$\alpha$ : slag residual ratio (dimensionless)

$\varepsilon$ : porosity of bed

$\mu: \quad$ viscosity of liquid $(\mathrm{gm} / \mathrm{cm} \cdot \mathrm{sec})$

$\rho:$ density of liquid $\left(\mathrm{gm} / \mathrm{cm}^{3}\right)$

$\Delta \rho:$ density difference between two liquid phases $\left(\mathrm{gm} / \mathrm{cm}^{3}\right)$

$\rho_{G}:$ density of gas phase $\left(\mathrm{gm} / \mathrm{cm}^{3}\right)$

$\rho_{I}:$ density of iron phase $\left(\mathrm{gm} / \mathrm{cm}^{3}\right)$

$\rho_{S}:$ density of slag phase $\left(\mathrm{gm} / \mathrm{cm}^{3}\right)$

$\phi:$ potential $(\mathrm{cm})$

$\nabla:$ 'del' vector operator

$\nabla^{2}:$ the Laplacian

\section{Acknowledgements}

The authors are grateful to Central Research Laboratories, the Broken Hill Proprietary Company Limited for their strong and continuing support of this work.

\section{REFERENCES}

1) T. Fukutake and K. Okabe: Proc. Int'l Symp. on Blast Furnace Hearths and Raceways, Aus. IMM Symp. Ser. No. 26, AIMM, (1981), 2-1.

2) T. Fukutake and K. Okabe: Trans. ISIJ, 16 (1976), 309.

3) T. Fukutake and K. Okabe: Trans. ISIJ, 16 (1976), 317.

4) J. Ohno, M. Nakamura and Y. Hara: Proc. Int'l Symp. on Blast Furnace Hearths and Raceways, Aus. IMM Symp. Ser. No. 26, AIMM, (1981), 10-1.

5) J. M. Burgess, D. R. Jenkins, M. J. McCarthy, L. P. Nowak, W. V. Pinczewski and W.B.U. Tanzil: Proc. Int'l Symp. on Blast Furnace Hearths and Raceways, Aus. IMM Symp. Ser. No. 26, AIMM, (1981), 9-1.

6) T. Shimozuma, T. Miyashita, K. Yamada and M. Otsuki: Tetsu-to-Hagané, 57 (1971), S346.

7) J. Bear: Dynamics of Fluids in Porous Media, Elsevier, N.Y., (1972).

8) W. V. Pinczewski, W.B.U. Tanzil, M. I. Hoschke and J. M. Burgess: Trans. ISIJ, 22 (1982), B202.

9) J. M. Burgess, M. J. McCarthy, D. R. Jenkins, W. V. Pinczewski and W.B.U. Tanzil: Symp. on Appl. of Math. \& Phys. Models in the Iron and Steel Industry, Proc. of 3rd Process Tech. Conf., Iron \& Steel Soc., AIME, Pittsburgh, Vol. 3, (1982), 15.

10) T. Tamiya, H. Shikata, K. Kobayashi, I. Ichihara, K. Okumura, T. Fukutake and H. Kawarada: Trans. ISIJ, 23 (1983), B114. 